\title{
A Prototype Mobile Robot for Intelligent Energy Harvesting in Emergent Situation
}

\author{
Lutfun Nahar Nipa \\ Department of Mechanical Engineering, \\ Rajshahi University of Engineering \& Technology \\ Rajshahi-6204, Bangladesh
}

\author{
Md. Rokunuzzaman \\ Department of Mechanical Engineering, \\ Rajshahi University of Engineering \& Technology \\ Rajshahi-6204, Bangladesh
}

\begin{abstract}
This paper describes a prototype mobile robot which will harvest energy when its own power reserve is diminishing while working. The need of power restoration of the mobile robot drives it automatically by auto plugging-in with the help of a microcontroller interfaced with a motor control circuit. For the development of the system a prototype mobile robot is made by designing of its various parts. The mobile robot firstly follows a line like a line following robot. With the movement of the robot, the battery charge will be decreased. When the charge decreases to less than 50\%, the mobile robot then follow the second line to recharge itself by auto plugging into the charging station. After getting fully recharged, the mobile robot again switched to follow the first line. A control circuit is designed to control the line following movement of the mobile robot. An algorithm is also developed circuit consists of infrared sensor, motor driver circuit with power supply, transmitter circuit, receiver circuit and infrared LED (IR-LED). DC motor is used as an actuator to control the wheel of the mobile robot. An infrared sensor is used to generate high and low frequency in the transmission circuit. High frequency is generated when capacitor's capacity is low and low frequency is generated when capacitor's capacity is high. The receiver circuit receives the high and low frequency and sends signal to the program that controls the DC motor according to the analysis result. Thus the DC motor drives the wheel to control the movement of the mobile robot. The overall success rate of the prototype mobile robot is $83.33 \%$ including line following and recharging.
\end{abstract}

\section{General Terms}

This project is worked with forward sensing control system. Forward sensing control uses sensors to step forward with other automatic guided vehicle in the area. There are many systems available for the development of this type of auto plug in system such as Laser Target Navigation , Steering control , Vision-Guidance, Forward sensing control system , Path select mode.

\section{Keywords}

Intelligent Energy Harvesting, Auto-recharging, Emergent Situation

\section{INTRODUCTION}

Power restoration of a mobile robot can be described as that mobile robot generally run by battery and in running process the battery charge decreased. So it is mandatory to supply electrical power to run the operation of robot in absence of power or scarcity of power. So in our project we have tried to develop a robot which will be able to seek power from electrical energy source by auto plug in otherwise it seeks energy by solar panel from solar source of energy. To develop the system robot technology, sensor, micro controller, solar panel etc. were used.

The robot will automatically guide itself around a room and through the use of an infrared sensor move towards a potential wall socket. When it reaches the socket, it will plug itself in to recharge. If we cannot get electrical energy by auto plugging in there should be a simple arrangement of solar panel controlled by the programmable micro controller that can collect energy directly from the sun. Otherwise if both operations failed then the robot will go to sleep mode or auto shut down occurs for power saving. There are many systems available for the development of this type of auto plug in system are following:-

$\begin{aligned} \text { i. } & \text { Laser Target Navigation } \\ \text { ii. } & \text { Steering control } \\ \text { iii. } & \text { Vision-Guidance } \\ \text { iv. } & \text { Forward sensing control system } \\ \text { v. } & \text { Path select mode }\end{aligned}$

In this project we work with forward sensing control system. Forward sensing control uses sensors to step forward with other automatic guided vehicle in the area.

In running the battery charge will decrease of the vehicle. To avoid manual charging in this project with the help of sensor to detect the charge of the battery and according to the charge of the battery the vehicle will automatically seek for electrical source to get electrical energy. After having electrical energy at desired level the vehicle will run for its working path.

The research of intelligent energy harvesting is almost new and very few literatures are available in the world. Intel developed a mobile robot which has the end effector (Power plug) containing an integrated electric field (E-Field) sensing electronics. The plug has antennas (electrodes) that sense the $60 \mathrm{~Hz}$ electric fields emanating from a powered outlet in order to facilitate highly-accurate plug-outlet localization and subsequent plugging-in [1]. Willow Garage invented PR-2 robots back in June 2009, is to employ visual techniques to facilitate plug-outlet localization. Plugging in was part of their wildly successful Milestone 2, where the PR-2 autonomously plugged itself into 9 different office outlets [2]. While early versions relied on a visual fiducially on the plug (check board pattern) and worked only on orange outlets. John Hopkins invented a self-plugging robot in 1960. That robot controlled by dozens of transistors, the Johns Hopkins University Applied Physics Lab's "Beast" wandered white hallways, centering by sonar, until its batteries ran low. Then it would seek black wall outlets with special photocell optics, and plug itself in by feel with its special recharging arm. After feeding, 
it would resume patrolling. Much more complex than Elsie, the Beast's deliberate coordinated actions can be compared to the bacteria hunting behaviors of large nucleated cells like paramecia or amoebae [3]. In 2002 Torres Jara invented a robot called Self-Feeding Robot." His robot bears a striking resemblance to the Beast robots of old, except that he used a two DoF linear actuator "arm" to plug itself in and located / localized outlets using boosted visual classifiers, while Roomba likes docking stations are an option for low-cost commercial robots [4].

In our work, we have devised a prototype mobile robot which will plug itself when it faces an emergency power problem. Our mobile robot is very simple in construction and made with parts locally available in the market.

\section{METHODOLOGY}

\subsection{System Overview}

In this system an automatic guided vehicle has been developed to auto plugging in due shortage of power in emergency situation. For this infrared LED is used to radiate continuously infrared ray and detect any reflection of these beams from the line to follow through the electrical source. At first vehicle drives at constant speed through the 1 st line \& with this moving if the vehicle charge goes under $50 \%$ then the vehicle automatically follow the 2nd line of moving to go towards the electrical source station to auto plug in. The main components of the circuit are DC motor, transistor, resistor, diodes and 8V DC supply. The system overview is shown in Figure 2.1.

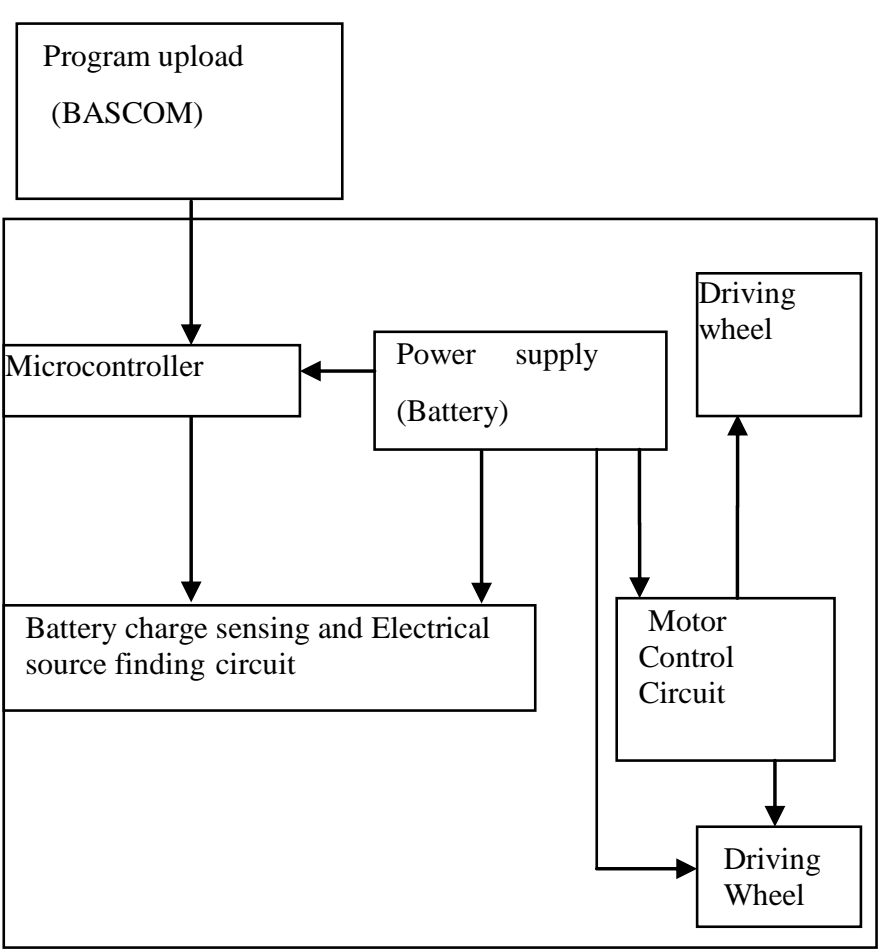

Figure 2.1: System overview

Here infrared sensor is used to generate high and low frequency in the transmission circuit [5]. High frequency is generated when capacitor's capacity is at low position and low frequency is generated when capacitor's capacity is high. Another circuit which is called receiver circuit, which receives the high and low frequency and analyze whether it is high or low frequency and sends signal to the program that controls the DC motor according to the analysis result. Variable resistor and capacitor is used for adjusting high and low frequency. Importance of this work is-

a. It can automatically sense the presence of line by following through it will move.

b. The user needs not to be a driver or need not even accompany the car.

c. A key goal is to achieve the desired electrical charge to run the robot vehicle.

\subsection{Methods and Tools Used}

Table 1: Specification of the System

\begin{tabular}{|c|c|}
\hline Item & Specification \\
\hline Language Used & $\mathrm{C}++$, BASCOM \\
\hline circuit animation & Protious-version 7.6 \\
\hline Microcontroller & AT mega8 \\
\hline
\end{tabular}

\subsection{Experimental Setup}

The experimental setup for auto plug in system is shown in Figure 2.2.The experimental setup mentions that there are mobile robot, charging station and wooden board where the lines for the line following robot to move on. The experimental setup mentions the overview of the system where a mobile robot seeks electrical energy for recharging itself in emergency situation.

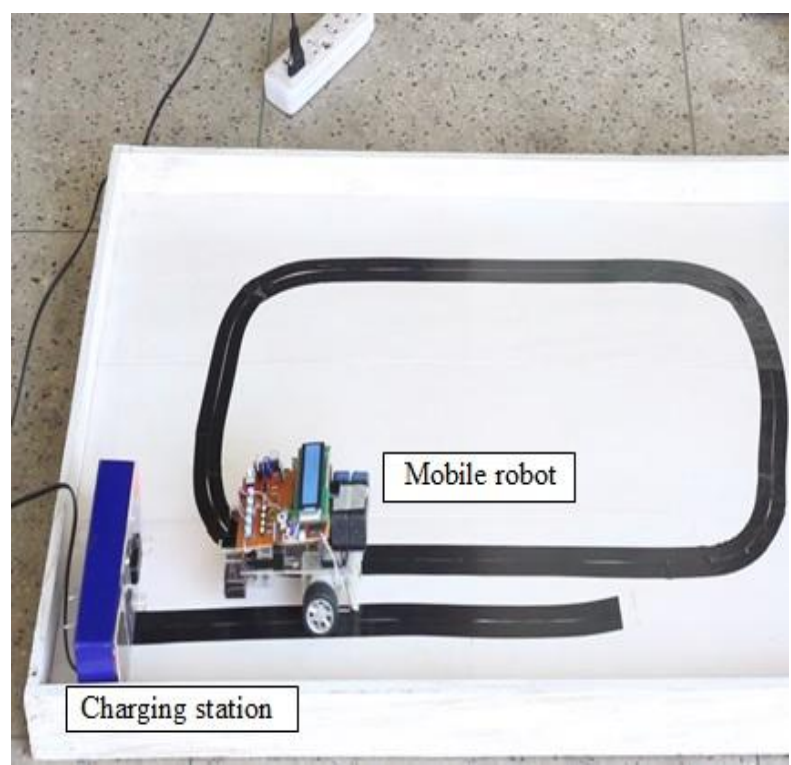

Figure 2.2: Experimental setup of the auto plug in system

The main components of setup are: Vehicle body, Base of the setup, Speed controller, DC motor, Infrared sensor, Light emitting diode, Rechargeable Battery, Microcontroller, Resistor, Control relays, Power supplies, Transistor, Charger and Connector cable.

\subsection{Line Following System}

In this project infrared sensor and infrared LED is used as sensor. Infrared (IR) sensors contain an emitting diode as well as a detector. Both the emitter and detector face in the same direction. If the sensor is pointed at nothing it returns a high value. If there is something nearby that reflects the IR light, then the value will be decreased. These sensors have an active range of approximately $2 \mathrm{~cm}$. The actual range depends on the reflectance and size of the object being detected. The line 
following system is shown in Figure 2.3.

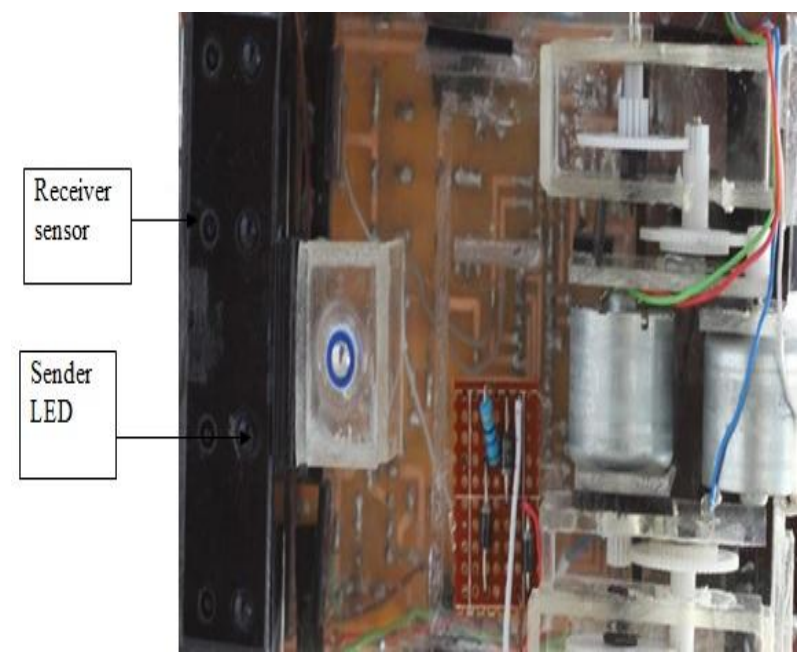

Figure 2.3: Line following system

\subsection{Controlling System}

Controlling system of the vehicle is completed by controlling the speed of DC motor. The speed of a DC motor is directly proportional to the supply voltage, so if we reduce the supply voltage the speed of the motor will reduce gradually. The speed controller works by varying the average voltage sent to the motor. It could do this by simply adjusting the voltage sent to the motor, but this is quite inefficient to do. A better way is to switch the motor's supply on and off very quickly. If the switching is fast enough, the motor doesn't notice it, it only notices the average effect. The controlling system is shown in Figure 2.4.

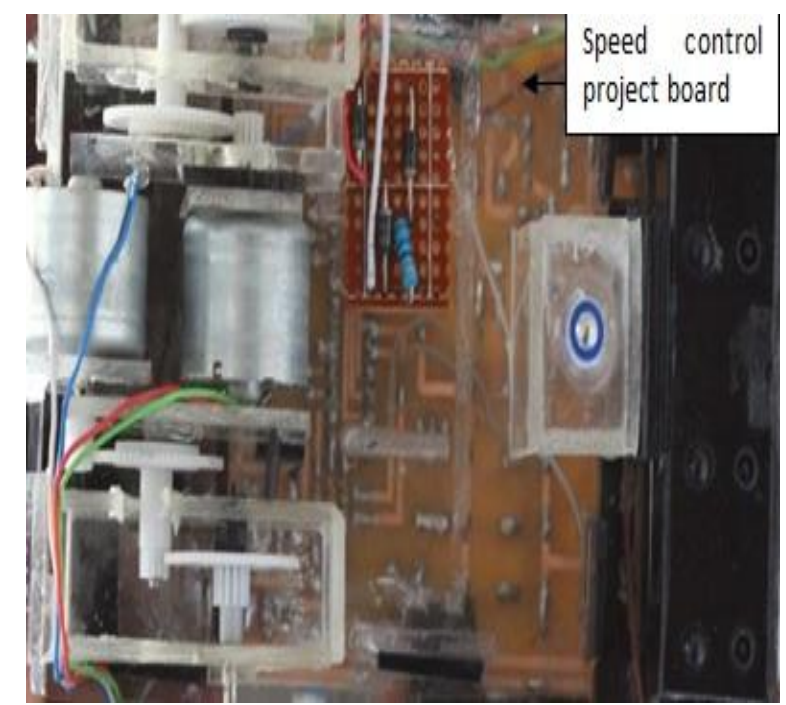

Figure 2.4: DC motor speed control board

\subsection{Mechanical System}

Mechanical system of the vehicle is completed by the modification of a toy car. Plastic is used for construction of car body. The body of a toy car is modified and mechanical system. There is also some pinion used for speed control in the mechanical system of the mobile robot. The mechanical system of the mobile robot helps to move smoothly. The mobile robot can be driven smoothly or can control the speed with the help of the mechanical system. The overall mechanical system is shown in Figure 2.5.

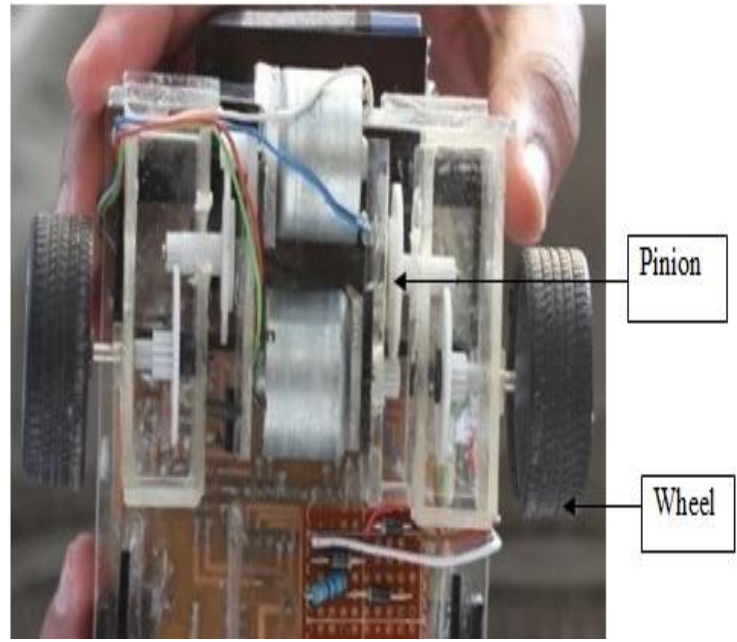

Figure 2.5: Mechanical system

\subsection{Battery Energy Meter}

In this system the battery charge status sends signal to the ADC transmitter through which the signal goes to the microcontroller circuit that sends the signal to the LCD where the battery energy status can show \& thus with the battery energy metering the vehicle follow the required path to get the desired charge which shown in Figure 2.6.

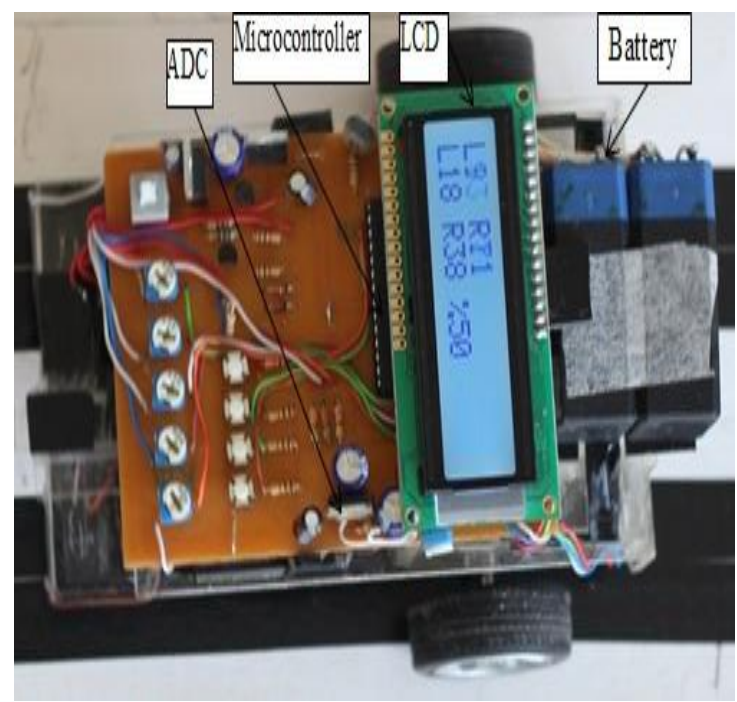

Figure 2.6: Battery energy meter

\subsection{Charging Station}

In the system there a charging station from where the mobile robot can get the electrical charge by auto plugging in the emergency situation. The mobile robot can go to the charging station by following the second line when it needs to get recharging. The charging station is shown in Figure 2.7. 


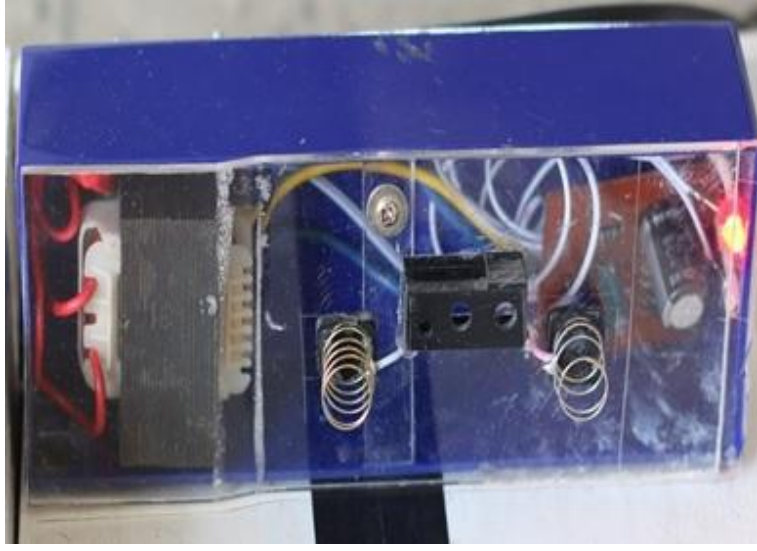

Figure 2.7: Charging station

\subsection{Microcontroller Pin Configuration PDIP}

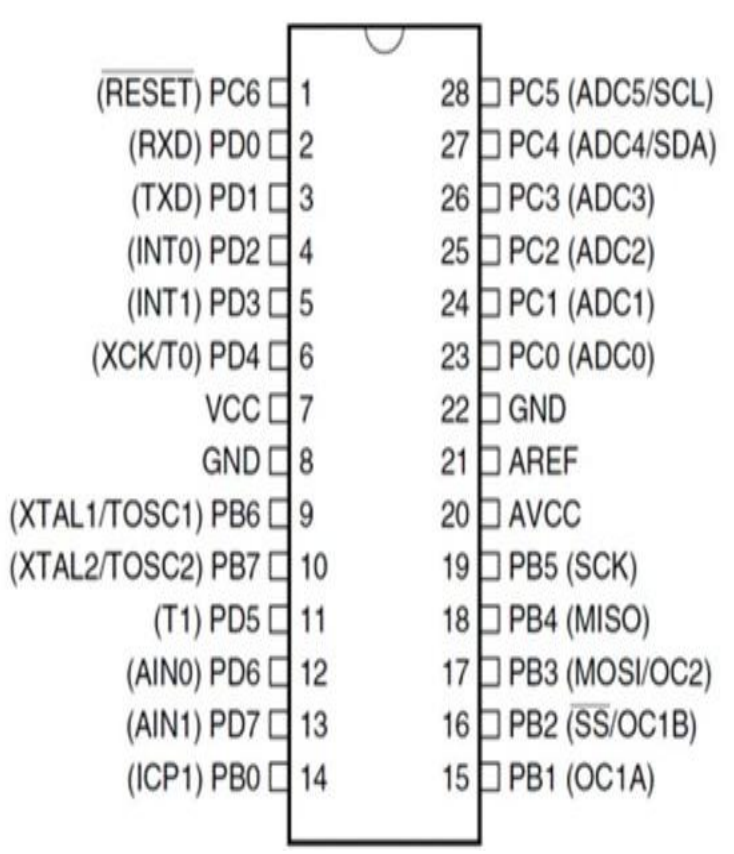

Figure 2.8: Pin out ATmega 8

Fig.2.8 shows the pin out of standard ATmega8 microcontroller by Atmel (AVR) Company. For the development of our system, we have used ATMega8 microcontroller for controlling the MU and DU and ATtiny44 for ID Card. Both ATMega8 and ATtiny44 is 8-bit controller produced by Atmel (AVR). Any other tiny controller may be used as ID Controller. The ATmega8 is a low-power CMOS 8-bit microcontroller based on the AVR enhanced RISC architecture. By executing powerful instructions in a single clock cycle, the ATmega8 achieves throughputs approaching 1 MIPS per $\mathrm{MHz}$ allowing the system designed to optimize power consumption versus processing speed. A standard pin description can be found in [6].

The power is supplied to the microcontroller from battery at pin 10 and 9 through resistor. Pin 11 is connected to ground. Pin 40 is connected to transmitter and receiver circuit. Pin 20 and 21 are connected to DC motor. Pin 22 to 25 are connected with stepper motor through resistor. The microcontroller circuit is shown in Figure 2.

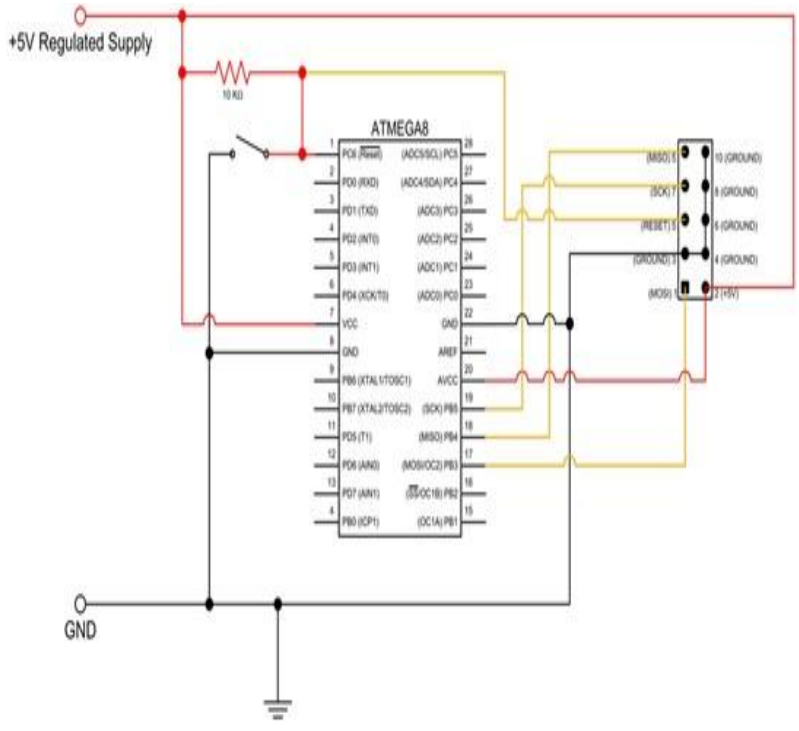

Figure 2.9: Microcontroller Circuit

\subsection{Block Diagram of Line Following System}

The block diagram of the line following system is shown in Figure 2.10. Here firstly the mobile robot indicates the contrast between black line and background white line. Then through the infrared sensor and infrared LED receiver passes the signal to the microcontroller circuit .Then through the driver circuit signal goes to the dc motor which drives the wheel. Thus mobile robot follows the path of the line [7]

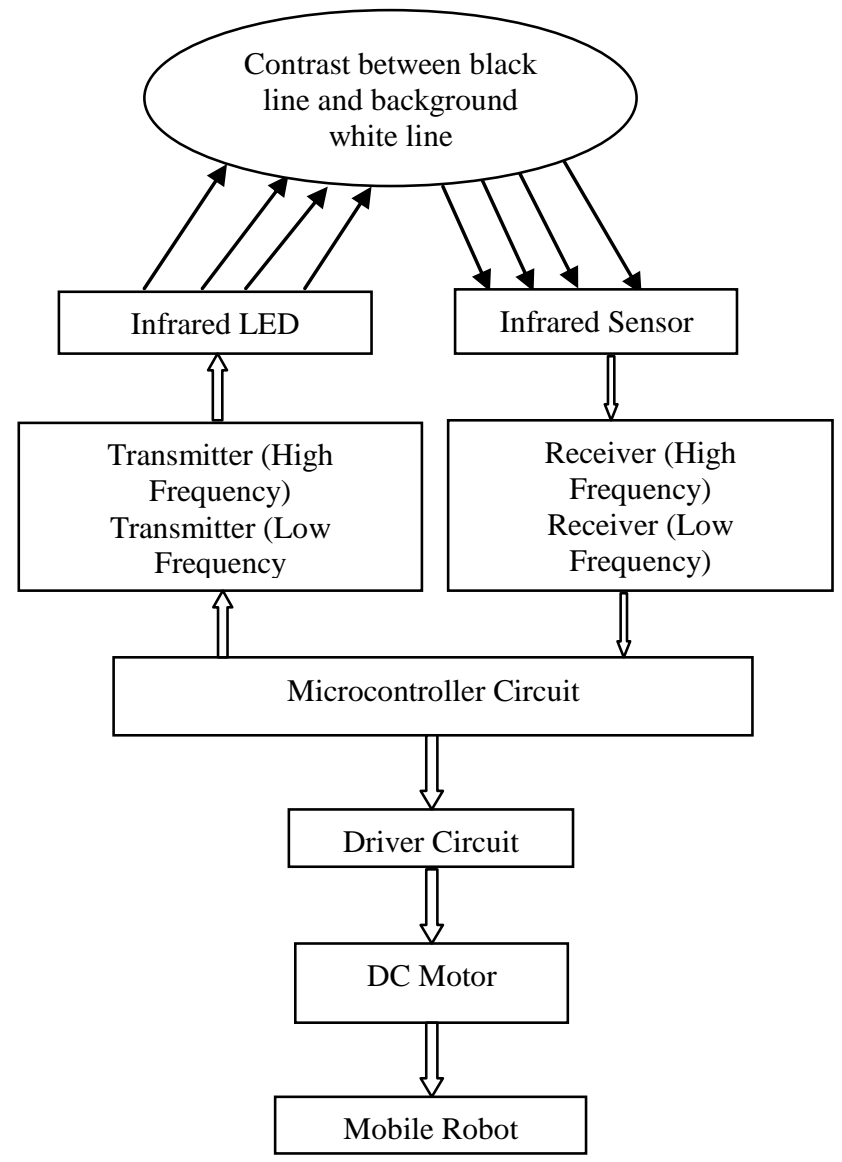

Figure 2.10: Block diagram of the line following system 


\subsection{Algorithms of the Line Following and Charging System}

The algorithm of the line following and charging system is shown in Figure 2.11.The flow chart shows that after starting the mobile robot check the charge status. If the charge is more than fifty percent the mobile robot follow the first line. With the following first line the charge will be decreased. If the charge decreases to the lower fifty percent the mobile robot then follow the second line to collect the charge by auto pluginto the charging station. Then with the increasing of charge up to fifty two percent the mobile robot automatically follow the first line of moving. The flow chart also shows that if the robot cannot get recharged station it will goes to sleep mode.

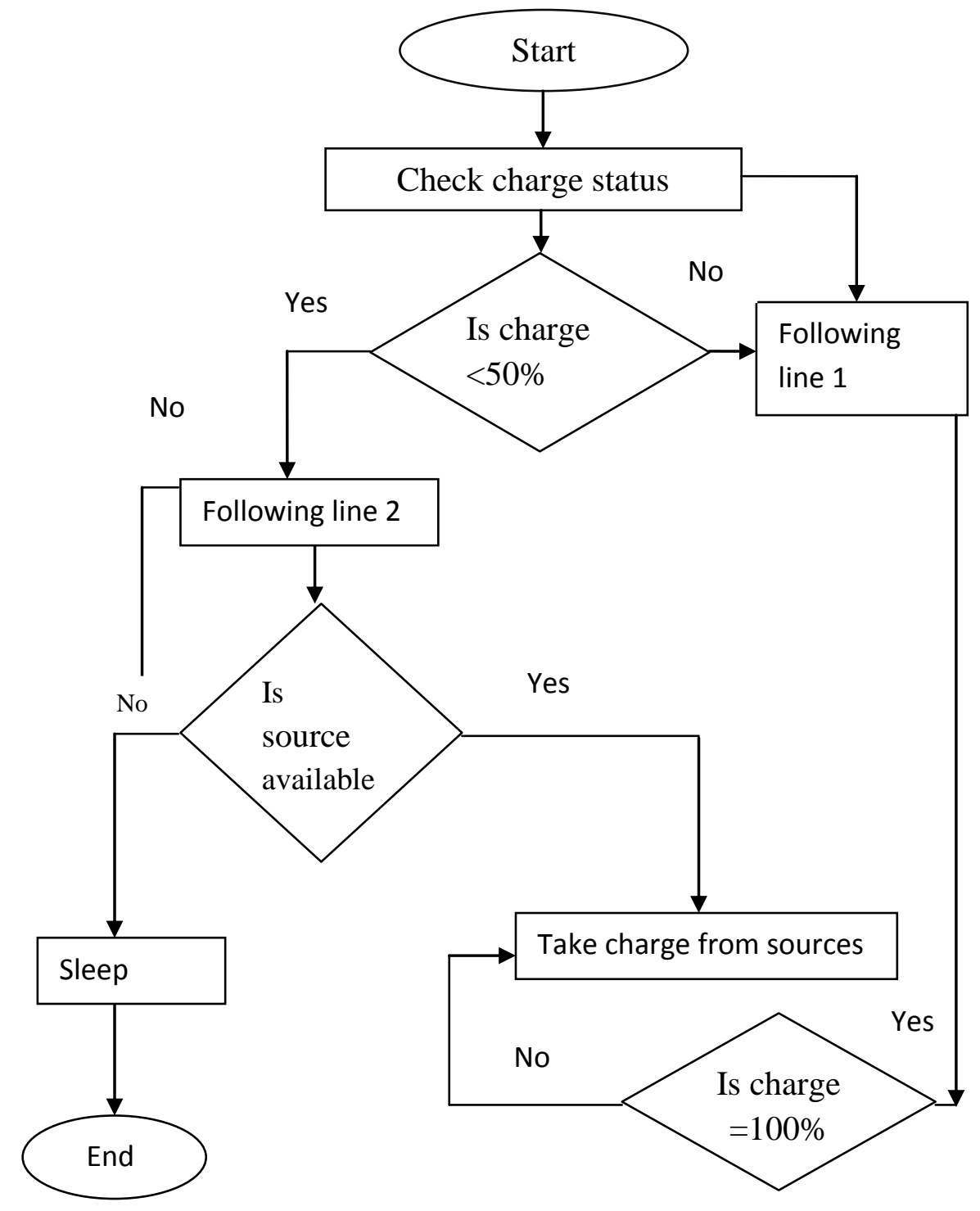

Figure 2.11: Algorithm of the Line Following and Charging System

\subsection{Motor Controller Driver Circuit for Rear Wheel}

DC motor driver circuits connected with microcontroller at pin 20 and 21 namely $\mathrm{T}_{1}$ and $\mathrm{T} 2$ through resistor. When $\mathrm{T}_{1}$ is closed, DC motor rotates clockwise and vehicle moves forward. When $T_{2}$ is closed, DC motor rotates anticlockwise and vehicle moves backward [8]. This is shown in Figure 2.12 .

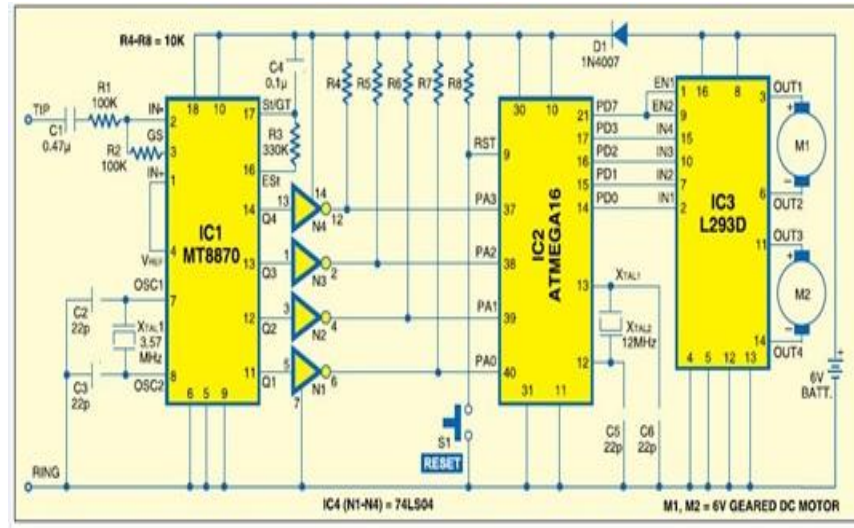

Figure 2.12: DC Motor Driver Circuit 
The speed of a DC motor is directly proportional to the supply voltage, so if we reduce the supply voltage from 12 Volts to 6 Volts, the motor will run at half the speed. How can this are achieved when the battery is fixed at 12 Volts? A better way is to switch the motor's supply on and off very quickly. The speed controller works by varying the average voltage sent to the motor. If the switching is fast enough, the motor doesn't notice it, it only notices the average effect. As the amount of time that the voltage is increases compared with the amount of time that it is off. It could do this by simply adjusting. We can see that the average speed is around 150, although it varies quite a bit. If the supply voltage is switched fast enough, it won't have time to change speed much, and the speed will be quite steady. As the amount of time that the voltage is increases compared with the amount of time that it is off. It could do this by simply adjusting the voltage sent to the motor, but this is quite inefficient to do. A better way is to switch the motor's supply on and off very quickly. If the switching is fast enough, the motor doesn't notice it, it only notices the average effect.

When we watch a film in the cinema, or the television, we are actually seeing is a series of fixed pictures, which change rapidly enough that our eyes just see the average movement. Our brain fills in the gaps to give an average effect. Now let us imagine a light bulb with a switch. When we close the switch, the bulb goes on and is at full brightness, say 100 Watts. When we open the switch it goes off (0 Watts). Now if we close the switch for a fraction of a second, and then open it for the same amount of time, the filament won't have time to cool down and heat up, and just get an average glow of 50 Watts. This is how lamp dimmers work, and the same principle is used by speed controllers to drive a motor. When the switch is closed, the motor gets 12 Volts, and when it is open it gets 0 Volts. If the switch is open for the same amount of time as it is closed, the motor will get an average of 6 Volts, and will run more slowly. A better way is to switch the motor's supply on and off very quickly. If the switching is fast enough, the motor doesn't get it, it only gets the average effect. As the amount of time that the voltage is increases compared with the amount of time that it is off, the average speed of the motor increases. We can see that the average speed is around 150, although varies quite a bit. If the supply voltage is switched fast enough, it won't have time to change speed much, and the speed will be quite steady. This is the principle of switch mode speed control. Thus the speed is set by PWM - Pulse Width Modulation [9]

\section{RESULTS}

\subsection{Line following sequences by mobile robot}

The constructed energy seeking vehicle is able to auto plug-in and charging automatically. In this system the LED transmitted ray which is reflected by the objects presents in front of the vehicle and receive by the receiver circuit. Then microcontroller circuit controls the DC motor by regulating the voltage. Then the vehicle search for alternative ways to move. Here some snap shots of the line following sequences are observed by the constructed mobile robot. The sequences are shown Figure 3.1, 3.2, 3.3, 3.4 and 3.5.

The Figure 3.1 and 3.2 shows the first line following sequences of the mobile robot. Four sample sequences of the movement of the mobile robot are shown here. The mobile robot firstly starts moving with the full charge of its battery and after some movement the battery charge gradually decreases. The mobile robot follows the first line till its

battery charge is greater than fifty percent of its full charge. The battery charge is shown on the LCD display with the help of the signal comes from the microcontroller through the ADC. Thus the mobile robot is driven with the direction comes from the microcontroller.

(A) $10 \mathrm{sec}$

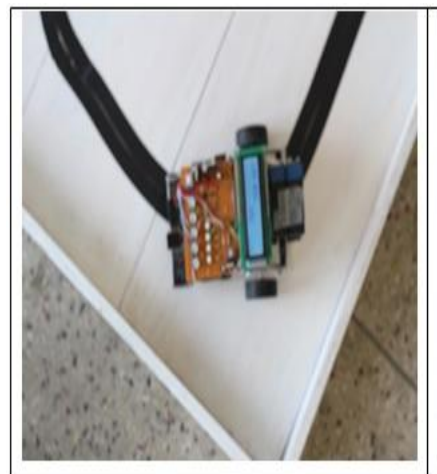

(C) $30 \mathrm{sec}$

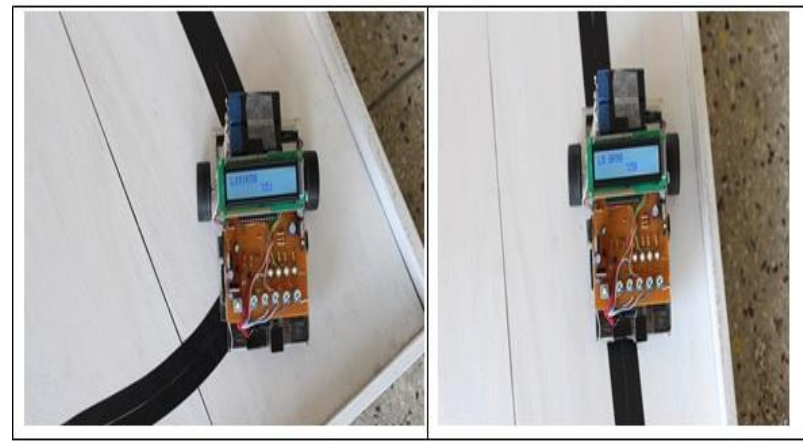

Figure 3.1: First line following sequences by mobile robot
(A) $48 \mathrm{sec}$

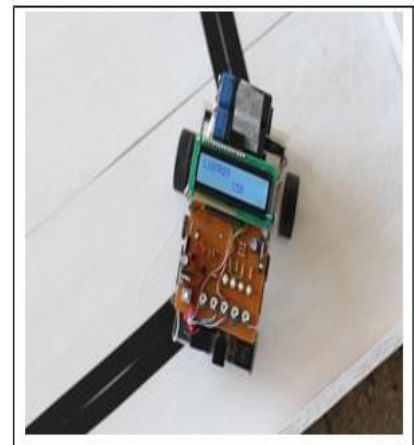

(C) $62 \mathrm{Sec}$

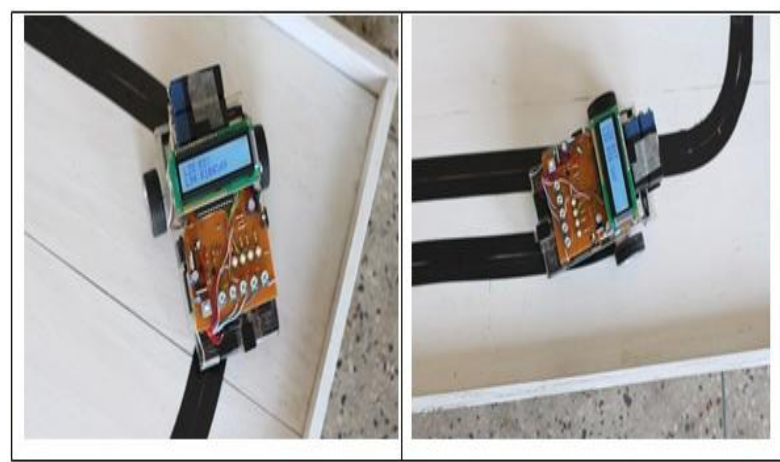

Figure 3.2: First line following sequences by mobile robot

(D) $65 \mathrm{Sec}$
(B) $20 \mathrm{Sec}$

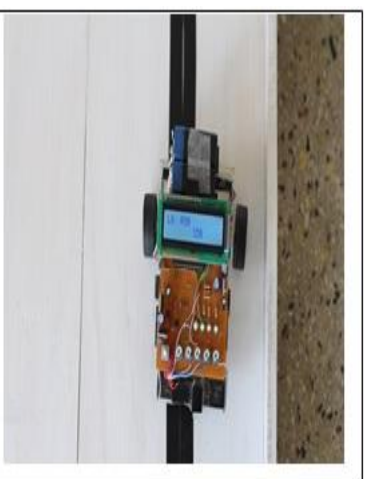

(D) $\quad 40 \mathrm{Sec}$

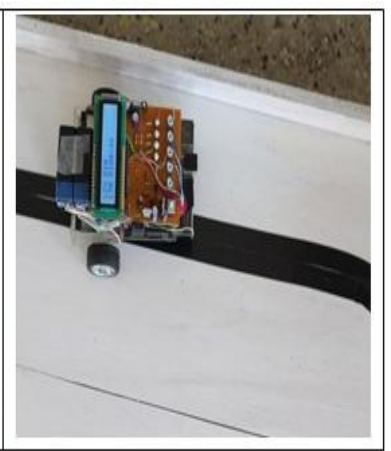

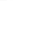


The Figure 3.3 mentions that the second line following sequences of the mobile robot. Sample two sequences of the movement of the mobile robot are shown here. When the battery charge becomes less than fifty percent, then the mobile robot switches to follow the second line for recharging by auto plugging into the charging station.

(A) $67 \mathrm{sec}$

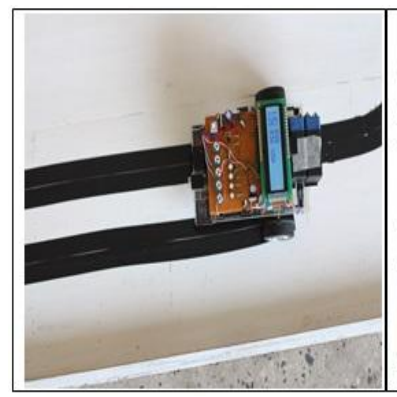

Figure 3.3: Second line following sequences by mobile robot

\subsection{Docking and recharging sequences}

(A) $75 \mathrm{sec}$

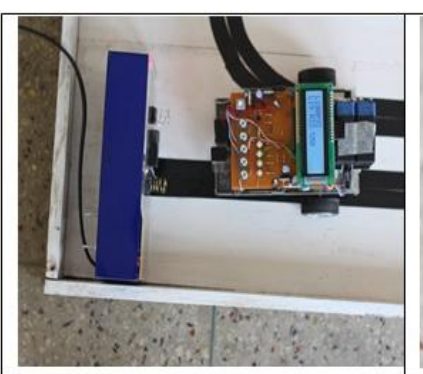

(B) $69 \mathrm{sec}$

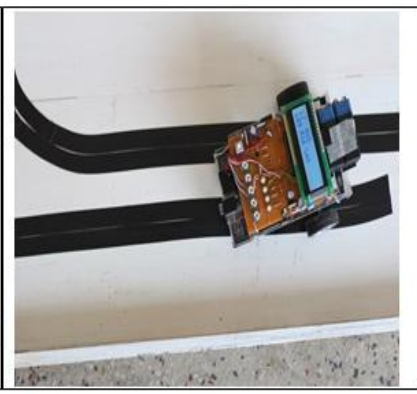

(B) $78 \mathrm{sec}$

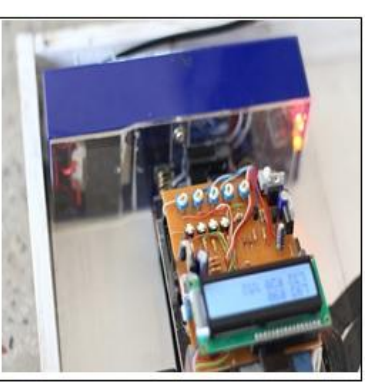

Figure 3.4: Docking and recharging sequences by mobile robot

Figure 3.4 shows the docking and recharging sequences by mobile robot. The docking is made by simply touching the spring which is connected to an external rechargeable battery charged by electric power supply. The recharging status is displayed by the LCD installed on top of the mobile robot.

\subsection{Undocking and first line following sequences}

The Figure 3.5 shows the undocking and first line following sequences of the mobile robot. Here the mobile robot takes the charge to recharge its battery. The battery gets full charge from the electrical source by auto plugging into the charging station. After recharging the mobile robot again follows the first line. Thus the mobile robot completes the energy seeking in emergency situation.

(A) $138 \mathrm{sec}$

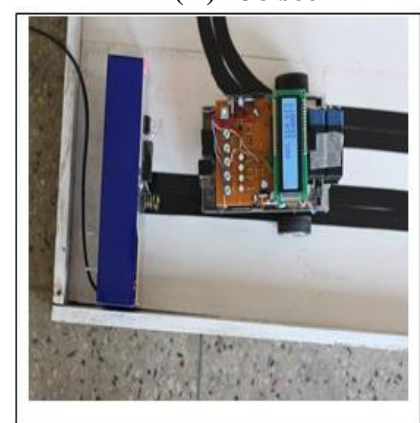

(C) $150 \mathrm{sec}$

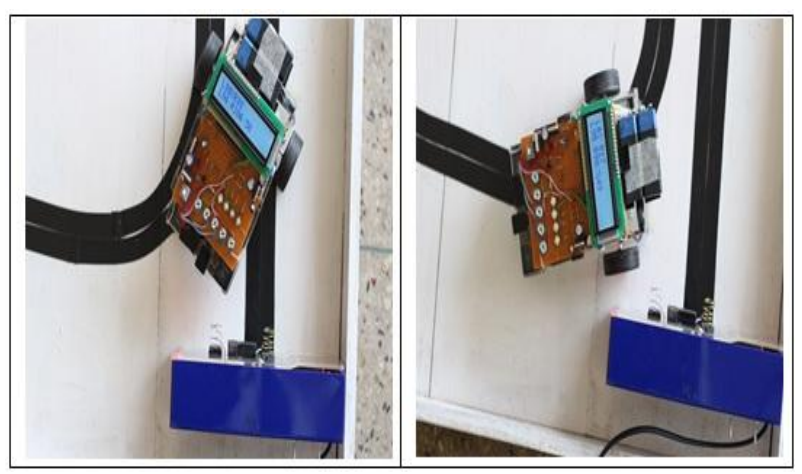

Figure 3.5: First line following sequences after recharging by the mobile robot

\subsection{Performance Evaluation of the system} Table 2: Experimental Data

\begin{tabular}{|c|c|c|c|c|c|}
\hline $\begin{array}{c}\text { No of } \\
\text { observa } \\
\text { tions }\end{array}$ & $\begin{array}{c}\text { First line } \\
\text { following }\end{array}$ & $\begin{array}{c}\text { Second } \\
\text { line } \\
\text { followin } \\
\mathbf{g}\end{array}$ & $\begin{array}{c}\text { Plug- } \\
\text { in }\end{array}$ & $\begin{array}{c}\text { Retur } \\
\text { n to 1 } \\
\text { st } \\
\text { line }\end{array}$ & $\begin{array}{c}\text { Total } \\
\text { time } \\
\text { (min) }\end{array}$ \\
\hline 1 & Yes & Yes & Yes & Yes & 2.15 \\
\hline 2 & Yes & Yes & Yes & Yes & 1.40 \\
\hline 3 & Yes & Yes & Yes & Yes & 1.56 \\
\hline 4 & Yes & Yes & Yes & Yes & 2.49 \\
\hline 5 & No & No & No & No & \\
\hline 6 & Yes & Yes & Yes & Yes & 1.35 \\
\hline 7 & Yes & Yes & Yes & Yes & 2.28 \\
\hline 8 & Yes & No & No & Yes & \\
\hline 9 & Yes & Yes & Yes & Yes & 2.16 \\
\hline 10 & Yes & Yes & Yes & Yes & 2.17 \\
\hline
\end{tabular}

The experimental data is shown in Table 2. Here the mobile robot firstly starts its movement with the first line following. If the first line following is yes and with the moving the battery charge will be decreased. When the battery charge is decreased to less than fifty percent then the mobile robot follows the second line of moving for auto recharging from charging station by plugging in automatically. If the second line following and recharging by plugging in is yes or successfully performed then the mobile robot again returns to the first line of following after getting fully recharged. The total time of the observation of the system is shown in very right hand side of the row.

From the Table 2 we can see that -

The fifth observation has shown no in every observation which indicates if the first line following is not performed successfully then rest of the observations would not be performed. As the eighth observation shows that the robot performed at first line successfully but it did not go through the second line and as it could not plugged in. But instead it was moving through the first line. This is how we have had some difficulties during the observation. Here we can find from table 2

Success rate $(\%)=$

$\frac{\text { Number of correctly line followed by the mobile robot }}{\text { Total number of trial }} \times 100 \%$ (1) 
Table 3: Success Rate

\begin{tabular}{|c|c|c|}
\hline Events & $\begin{array}{c}\text { Success } \\
\text { Rate }\end{array}$ & $\begin{array}{c}\text { Overall } \\
\text { Success Rate }\end{array}$ \\
\cline { 1 - 2 } $\begin{array}{c}\text { First line } \\
\text { following }\end{array}$ & $90 \%$ & \multirow{2}{*}{$83.33 \%$} \\
\cline { 1 - 2 } $\begin{array}{c}\text { Second line } \\
\text { following }\end{array}$ & $80 \%$ & \\
\cline { 1 - 2 } Recharging & $80 \%$ & \\
\hline
\end{tabular}

From the Table 3 we can see that the success rate of the first line following is $90 \%$, as the second line following and recharging is $80 \%$. The performance of system is good. The mobile robot can seek energy and automatically plug-in into the charging station. Thus this energy seeking system can be defined as intelligent system. The successful operation percentage is about $83.33 \%$ for the observations.

\section{CONCLUSION}

In automatic guided vehicle, the vehicle automatically senses the presence of electrical station in front of the vehicle and auto plug in. Some improvements in the performance can be achieved by changing the components used (e.g. high range sensor for receiver circuit). Automatic guided vehicle will not be able to obey oral instructions from policeman, so a digital system will have to be developed. Toy car is used for the design and construction of the vehicle is made as required to fulfill the objectives. In automobile sector computer controlled software is used to control the vehicle. However we have used microcontroller because of Low cost, Simplicity in design, Greater flexibility, Low weight and less space requirement facility. If high range (ultrasonic sensor) sensor is used, it can easy to detect the long distance object. For control the vehicle efficiently, program also be updated requirement. If receiver and transmitter circuit can develop, high accuracy may be achieved. Image processing software may be used for identifying the electrical source station. However the automatic guided vehicle developed is performed satisfactorily as required. The designed prototype robot is able to recharge automatically. This robot can be used for information seeking or many complex purposes where human cannot able to go physically. Our robot is able to avoid manual plug-in. It can save energy in scarce of source of energy. In future, we would like to extend algorithms for harvesting energy when the electric source is unable to power up as in case of load shedding or any other power failure. In this case, the mobile robot will switch its path to seek energy from some alternative source of power. The alternate source can be a solar power station or it can be built-in Photovoltaic panels installed in the robot itself. As like other existing systems, our system can be improved by installing an electrical sensor for seeking electric source which will make the robot much smarter than following a line.

\section{REFERENCES}

[1] Travis Deyle, "Self-feeding robots: Robots that Plug Themselves Into Wall Outlets, article, available at http://www.hizook.com

[2] Personal Robotics, Mobile Manipulation, Robot for research and innovation, available at http://www.willowgarage.com/pages/pr2/overview

[3] The Johns Hopkins Beast, article from Jeremy Norman \& Co., Inc. available at http://www.historyofinformation.com/expanded.php?id= 4190

[4] Eduardo R. Torres-Jara, “A Self-Feeding Robot", Master Thesis, MIT, 2002

[5] Boylestad R.L and Nashelsky L., "Electronics Devices and Circuit Theory", 8th Edition, Prentice Hall, 2002

[6] Rakesh, "Avr Atmega8 Microcontroller - An Introduction", article, February 14, 2012, available at http://www.circuitstoday.com/avr-atmega8microcontroller-an-introduction

[7] Apostolopoulos, D., Wagner, M. and Whittaker, W. "Technology and field demonstration results in the robotic search for Antarctic meteorites", Proc. of the Int. Conf. on Field and Service Robotics, pp. 185 -190, 1999

[8] David Bodanis "Electric Universe: the Shocking True Story of Electricity", Crown Publishers, New York, 2005

[9] Heil, Oskar, "Improvements in or relating to electrical amplifiers and other control arrangement and devices", Patent No. GB439457, European Patent Office, filed in Great Britain 1934-03-02, published 1935-12-06 (originally filed in Germany 1934-03-02). 